\title{
LEAF CONSUMPTION IN THE REARING OF SILKWORM WITH HIGH HUMIDITY METHOD
}

\author{
Nasirillaev Bakhtiyar Ubaydullaevich \\ Doctor of Agricultural Sciences, Professor, Sericulture Research Institute of Uzbekistan, \\ Tashkent, Uzbekistan
}

\author{
Sodikov Davron Sodik ugli \\ Independent researcher, Sericulture Research Institute of Uzbekistan, \\ Tashkent, Uzbekistan
}

Article DOI: https://doi.org/10.36713/epra6118

\begin{abstract}
In silkworm rearing in Uzbekistan, one of the main problems is the maintenance of a hygrothermal regime. Scientific research has been carried out to create optimal air temperature and relative humidity for rearing hybrid silkworms from the 1 st instar to the 5th instar. In the experiments, the silkworms were fed in two different experiments and in the same comparative method. In silkworm rearing, the use of fabric and polyethylene film to retain humidity in a special device has been found to save mulberry leaf consumption by 15,3-18,7\%, and to shorten the worm cycle by 2,7-4,0 days and due to maintaining the hygrothermal regime, a significant increase in silkworm growth and weight was observed.
\end{abstract}

KEYWORDS: silkworm, mulberry leaves, temperature, humidity, cocoon, silk.

\section{INTRODUCTION}

Silk is produced in more than 60 countries around the world, with the People's Republic of China accounting for the bulk of the cocoon's raw material. In the world silk market, the demand for cocoon products that produce silk fibers with a high metric number (fine) is growing year by year. The main demand of cocoon processing enterprises of the leading silk-producing countries is for silk yarns of types $3 \mathrm{~A}, 4 \mathrm{~A}, 5 \mathrm{~A}$. In the modern era of market relations, the production of competitive products in the world market of exportoriented products is of great priority. In the silk industry, best quality silk depends mainly on the quality and properties of the cocoon. Improving the quality of raw silk can be achieved through the application of new innovative technologies in the production of silk products using a variety of technologies.

In this regard, at present labour work is not accepted in the countries with developed sericulture, but the role of innovative technologies in the care of mulberry silkworms is of great importance. Therefore, the use of innovative techniques and technologies in the period of mechanization and rearing of silkworms will facilitate the provision of quality raw materials in the production.

For preparing industrial seeds of silkworm, Sh.A.Sherbakov created a device to determine sex of coccon based on their weight. B.A.Strunnikov proposed a method of obtaining breeding cocoons using the apparatus - Cocoon shell mass determiner, depending on the thickness of the cocoon shell obtained for breeding, and as a result it was proved that it is possible to increase the silkiness of cocoons [1].

While scientists in the field of sericulture have done a lot of research on shortening silkworm rearing period and producing abundant and quality cocoons, the advanced cocoon producers have also introduced a number of innovations into silkworm rearing processes in their practical experiments. As a result, several methods have been developed in silkworm rearing, such as simple method, intensive method and the method of silkworm breeding at changeable temperature, as well as an 
improved method. Today, an improved intensive method is being used widely. For this, it is required the temperature to be $26-27^{\circ} \mathrm{C}$ and relative humidity to be 65 $75 \%$ in the $1 \mathrm{st}, 2$ nd and 3 rd instars of silkworm, in the 4 th instar to be $25-26^{\circ} \mathrm{C}$, in the 5 th instar $24-25^{\circ} \mathrm{C}$, while in cocooning stage $25^{\circ} \mathrm{C}$, with humidity 60-65 percent [2]. In the result of rearing silkworm under this improved intensive rearing method, larva stage of reared silkworms reduced by 1-1,5 days, cocoon yield, mean weight of cocoon and silk-fiber yield increased by 4-5 percent.

The amount of the food given to the silkworm, eaten and digested by the worm body depends on the amount of water in the leaf, the moisture and freshness of the leaf. In cocoonery where the silkworms are reared, when the temperature is $25-27^{\circ} \mathrm{C}$, the mulberry leaves lose freshness within 1,5 hours and get dried. Young larva of silkworm consume the leaves slower than the larva of older instar. In the rearing of young larva, the care under polyethylene film is much more effective. As a result of this, if the larva are fed at regular intervals, i.e 3 times a day with chopped leaves, the growth of worms is accelerated and the freshness of mulberry leaves remains more, getting less dried. The most part of the given feed, that is mulberry leaves are saved to be wasted. It was found that when a mulberry silkworm is fed in a simple way, 100-1200 kgs of leaves are consumed per box of worms, and when fed under film, an average of $750-800 \mathrm{kgs}$ of food is consumed per box of worms [6].

When silkworms are reared under ordinary conditions, the moisture of the mulberry leaf quickly decreases and begins to dry out. By considering the worm's need for humidity, it has been suggested that young larva can be fed 4-5 times a day instead of 9-10 times a day if they are fed under a damp sheet/blanket cover or polyethylene film [2].

Mulberry silkworms need to be fed on special shelves to protect them from pests and floor (ground) moisture. Folding shelves and permanent stillages (racks) are used to rear the silkworm of all instars. They can be installed vertically in 2,3,4 and 8-10 layers [2].

In the method that is used in India, it is recommended to rear mulberry silkworm larvae in young and adult instars in special boxes measuring $2 \times 3 \mathrm{~m} \mathrm{[5]}$. In the rearing process of the silkworm in these stillages the work can be accelerated and get easier. For feeding and thinning the silkworm larva, it has been noted that the time is saved by 23 percent to 60 percent. Furthermore, the damage that can be caused to larva reared in these stillages while changing their place, or transferring somewhere has been found to be decreased.

At the stage of cocooning of silkworm, the quality of cocoon, its calibre, i.e large or small sizes, shape, weight, shell mass, silkiness, cocoon hardness and technological indicators not only depend on silkworm breed, but also on cocooning condition too [2, 3, 4]. The authors reported that the temperature, humidity and light in cocooning condition, as well as the amount and quality of mulberry leaves may affect considerably to cocooning.

The cost of growing mulberry silkworm and producing cocoon products is increasing. This is due to the fact that as a result of the decline in the quality of the cocoons grown, the fineness of the silk fiber is not at the level required by world standards. That is, nonrecommended materials for silkworm rearing are used in the production process. It leads to defective formation of cocoons which are double, spotted and have a rack trace. The use of the proposed artificial trays of polyethylene, cardboard and other materials has been proven to improve the quality and technological performance of cocoons $[7,8]$.

\section{MATERIALS AND METHODS}

The research was carried out in 2018-2020 in the ecological rearing facilities of the Uzbek Sericulture Research Institute. The experiments were performed on a Line $27 \times$ Line 28 industrial hybrid of mulberry silkworm created at the institute. The experimental worms were fed with a mixture of mulberry leaves brought from the mulberry plantations of the "Jararik" experimental station. These special rearing facilities and mulberry leaves were used for second silkworm rearing, just like in the spring season. The special rearing bed with trays was made in the workshop of the laboratory "Mechanization of silkworm breeding" of the institute.

In the experiments on rearing hybrid silkworms under damp cloth and film, leaf consumption, air temperature, relative humidity, amount of consumed and wasted leaves, larva weight, cocoon weight, silkiness, capability for breeding and the most important technological indicators of cocoon were determined by variants according to the scheme of the experiment of the research carried out for three years.

Nowadays, in order to get a high cocoon yield from silkworms, it is necessary to use the agronomic techniques of silkworm feeding properly, along with rearing good industrial hybrids of silkworms. In our experiments, the silkworm larva were reared under the damp sheet (blanket) and polyethylene film in their I-V instars to prevent the silkworm food - mulberry leaves from drying out while bringing them, storing and feeding, as well as during their consumption. In our second experiment, the silkworms of young instars (I-III) were reared under damp sheet and film. For this, the humidity under the blanket and film is to be high (80$90 \%)$ and the temperature is low $\left(22-24^{\circ} \mathrm{C}\right)$. As a result, the leaves retain moisture, do not dry up, and silkworms larva consume the leaf. To further increase the efficiency of feeding the larva under a blanket sheet and polyethylene film, we gave them mulberry leaves in different order. For example, they were fed 3, 4, 5 times a day and the results were recorded. During the experiment, the supply of more leaves of good quality to silkworms was achieved at their adult stage by saving mulberry leaves to be given to their younger instar stage. 


\section{EPRA International Journal of Research and Development (IJRD) \\ Volume: 6 | Issue: 1 | January 2021 - Peer Reviewed Journal}

Using this method, cocoon yield of good quality was obtained even during second silkworm rearing seasons. To do this, silkworms were fed as in the spring, and attention was paid to temperature and humidity. During the second rearing period, silkworms were fed with mulberry leaves mainly 4 times a day, and the results were recorded. It is noteworthy that when the silkworms of second rearing were fed in the laboratory, it was possible to obtain a cocoon yield of $50-55 \mathrm{~kg}$ per 1 box. The cocoon weight was also a bit heavier than the comparator.

\section{RESULTS AND DISCUSSION}

The main purpose of our experiments to be conducted in high humidity condition was firstly, to retain longer the moisture of mulberry leaves, secondly, to reduce leaf consumption. For this, three experimental variants were made in a new type of rearing bed with trays: 1. Rearing silkworm under polyethylene film; 2 . Rearing under blanket (sheet); 3. Rearing with simple method. In each variant, silkworm was reared by 800 pieces. During I-V-instars period, larva were fed 64 times with leaves. At the I-instar, they were fed 10 times; at the II-instar 10 times; at the III-instar 10 times; IV- 11 times; V-instar 23 times. The leaves were weighed before each feeding. During the experiments the weight of silkworms of III, IV, V-instars was determined and also the leaf consumption was recorded each time (Table 1).

Having analyzed the data presented in table- 1 about a three-year research results on the method of rearing silkworms of new Line $27 \times$ Line 28 industrial hybrid under damp blanket, we can see that leaf consumption by years didn't differ much from each other. This indicator made average $13294,8 \mathrm{~g}$ for 3 years. Mean temperature was $24,30 \mathrm{C}$, humidity was $83,8 \%$. It is noteworthy that a high level of relative humidity was maintained in the experiments. While rearing silkworm in this method, the larva period made 26,0 days; 26,0; 28,5 days respectively by years. The average three-year larva period was 26,8 days. It should be emphasized that the number of leaf feeding the larva was 76,6 times during their I-V instars.

The next method of rearing silkworms in high humidity was to care for the worms under a film, which allowed us to cover the film tightly to our newly constructed rearing bed. The goal from this method was to minimize leaf moisture loss and create a microclimate for silkworms.

Table 1

Leaf consumption in rearing Line $27 \times$ Line 28 hybrid silkworms under sheet cover (average indicators for 2018-2020)

\begin{tabular}{|c|c|c|c|c|c|c|}
\hline Silkworm instar & $\begin{array}{c}\text { Number } \\
\text { of feeding } \\
\text { with } \\
\text { leaves }\end{array}$ & $\begin{array}{c}\text { Weight of } \\
\mathbf{1 0 0} \mathbf{~ p c s} \text { of } \\
\text { larva, }\end{array}$ & $\begin{array}{c}\text { Leaf } \\
\text { consumption, } \\
\mathbf{g}\end{array}$ & $\begin{array}{c}\text { Temperature } \\
\mathbf{0} \mathbf{C}\end{array}$ & $\begin{array}{c}\text { Relative } \\
\text { humidity, } \\
\mathbf{\%}\end{array}$ & $\begin{array}{c}\text { Larva } \\
\text { stage, day }\end{array}$ \\
\hline I - instar & 13 & & 88,06 & 24,0 & 82,5 & 4,2 \\
\hline II - instar & 11,3 & & 294,0 & 24,4 & 83,0 & 4,7 \\
\hline III - instar & 12 & $3,94 \pm 0,02$ & 1003,3 & 24,6 & 83,8 & 4,5 \\
\hline IV - instar & 14 & $19,1 \pm 1,12$ & 2398,6 & 24,2 & 83,7 & 5,8 \\
\hline V - instar & 26,3 & $96,02 \pm 0,26$ & 9484,1 & 24,2 & 81,8 & 7,7 \\
\hline Total & 76,6 & & 13294,8 & mean 24,3 & mean 83,8 & 26,8 \\
\hline
\end{tabular}

Table 2

Leaf consumption in rearing Line $27 \times$ Line 28 hybrid silkworms under film cover (average indicators for 2018-2020)

\begin{tabular}{|c|c|c|c|c|c|c|}
\hline $\begin{array}{c}\text { Silkworm } \\
\text { instar }\end{array}$ & $\begin{array}{c}\text { Number of } \\
\text { feeding } \\
\text { with leaves }\end{array}$ & $\begin{array}{c}\text { Weight of } \\
\mathbf{1 0 0} \mathbf{p c s} \text { of } \\
\text { larva, }\end{array}$ & $\begin{array}{c}\text { Leaf } \\
\text { consumption, } \\
\mathbf{g}\end{array}$ & $\begin{array}{c}\text { Temperature } \\
\mathbf{0} \mathbf{C}\end{array}$ & $\begin{array}{c}\text { Relative } \\
\text { humidity } \\
\mathbf{\%}\end{array}$ & $\begin{array}{c}\text { Larva } \\
\text { stage, } \\
\text { day }\end{array}$ \\
\hline I - instar & 12,7 & & 112,8 & 26,0 & 55,9 & 4,2 \\
\hline II - instar & 10,3 & & 285,7 & 25,5 & 63,9 & 4,2 \\
\hline III - instar & 11,3 & $3,91 \pm 0,06$ & 925,7 & 25,3 & 64,6 & 4,3 \\
\hline IV - instar & 13,3 & $24,26 \pm 1,54$ & 2116,3 & 25,4 & 76,0 & 5,2 \\
\hline V - instar & 25,7 & $123,57 \pm 1,38$ & 9268,7 & 25,2 & 84,1 & 7,7 \\
\hline Total & 68 & & 12709,0 & 25,5 & 80,9 & 25,5 \\
\hline
\end{tabular}




\section{EPRA International Journal of Research and Development (IJRD)

It is clear from the figures given in table-2 that the use of film in the rearing beds allowed to retain humidity inside in high level. During the years 2018-2020, this indicator was equal to $70,4-86,6 \%$, was found to be average $80,9 \%$.

As for the air temperature, this figure averaged $25,5^{\circ} \mathrm{C}$. Most importantly, the temperature remained the same for three years. This allowed the silkworm to grow and develop normally.

Our observation of leaf consumption shows that silkworm rearing under the polyethylene film not only retains moisture, but also reduces leaf consumption. A three-year leaf consumption was $13219,0 \mathrm{~g} ; 10534,5 \mathrm{~g}$; $14374,4 \mathrm{~g}$ respectively, and average $12709,0 \mathrm{~g}$, comparing to silkworm rearing method under damp blanket, 585,8 g less leaves were used.
Analysis of larva period indicate that during the three-year experiments the larva period of I-V- instars constituted 24,5-26,5 days, average 25,5 days.

The next method we used was a simple traditional silkworm rearing method (comparative), in which the worms are kept in the rearing bed not covered with something as usual. It should be noted that in different climatic conditions of our regions, it has been observed that the leaves for feeding silkworm quickly lose moisture, dry up and reduce feed efficiency, as well as over-consumed. Along with silkworm rearing methods under film and damp blanket sheets, we reared the worms in an open manner and determined leaf consumption, larva period, air temperature and humidity.

Table 3

Leaf consumption in rearing Line $27 \times$ Line 28 hybrid silkworms under simple method (average indicators for 2018-2020)

\begin{tabular}{|c|c|c|c|c|c|c|}
\hline $\begin{array}{c}\text { Silkworm } \\
\text { instar }\end{array}$ & $\begin{array}{c}\text { Number of } \\
\text { feeding with } \\
\text { leaves }\end{array}$ & $\begin{array}{c}\text { Weight of } \\
\mathbf{1 0 0} \mathbf{~ p c s} \text { of } \\
\text { larva, } \mathbf{g}\end{array}$ & $\begin{array}{c}\text { Leaf } \\
\text { consumption, } \\
\mathbf{g}\end{array}$ & $\begin{array}{c}\text { Temperature, } \\
{ }^{\circ} \mathbf{C}\end{array}$ & $\begin{array}{c}\text { Relative } \\
\text { humidity, } \\
\mathbf{\%}\end{array}$ & $\begin{array}{c}\text { Larva } \\
\text { stage, } \\
\text { day }\end{array}$ \\
\hline I - instar & 32 & & 139,2 & 25,9 & 73,9 & 4,8 \\
\hline II - instar & 26,3 & & 371,2 & 26,0 & 71,4 & 5,0 \\
\hline III - instar & 30,7 & $3,52 \pm 0,28$ & 1290,5 & 26,0 & 70,2 & 4,8 \\
\hline IV - instar & 25,7 & $16,83 \pm 1,63$ & 2508,0 & 26,3 & 71,4 & 6,8 \\
\hline V - instar & 43,7 & $78,92 \pm 1,08$ & 11322,0 & 26,2 & 70,5 & 8,0 \\
\hline Total & 158 & & 15630,8 & 25,9 & 70,8 & 29,5 \\
\hline
\end{tabular}

From the analysis of the figures given in table 3 , it can be seen that in this comparative method the leaf consumption increased significantly. It has also been observed that the number of feeding with leaves at the 5th instar was also very high, i.e, in 2018 mulberry leaves were given to silkworm total 166 times, in 2019 172 times and in 2020136 times. During the three years leaf feeding was average 158 times. If we compare it with the methods of silkworm rearing under film and blanket, we can see that leaf feeding was done by $82-90$ times more.

Leaf consumption results at the fifth instar of silkworms support these abovementioned comparisons. Because in 2018 the leaf consumption made 17333,2 g; in $201912352,7 \mathrm{~g}$ and in 2020 it was $17206,5 \mathrm{~g}$, average $15630,8 \mathrm{~g}$. When simple method was compared to the methods of silkworm rearing under the film and blanket, it led to overconsumption of additional 2336,0-2921,8 $\mathrm{g}$ or 2,3-2,9 kg leaves.

As for larva period of silkworm in simple method of rearing, it made 28,5 days in 2018; in 2019 29,5 days and in 202030,5 days. A three-year average indicator was 29,5 days. If it is compared to rearing under the film and cloth, larva period of silkworm was found to increase by 2,7-4,0 days. In its turn, it can lead to additional labor, leaves for feeding, and additional money for costs in sericulture.

\section{CONCLUSION}

If we consider climatic conditions of Uzbekistan, a sharp change is noted in air temperature and humidity in silkworm rearing seasons. Under such conditions, it is required to create an optimal hygrothermal regime for silkworms in order to grow the maximum cocoon yield. Otherwise, it will not be possible to take full advantage of the genetic potential of industrial hybrids. In this research, mulberry silkworms were reared in three different methods, and the method of rearing silkworm under a damp cloth and polyethylene film was recommended for optimal silkworm rearing. The data obtained proved that the leaf needed to care for the silkworm could be significantly saved and the temperature and humidity could be kept at a level normal for silkworms by shortening the larva period.

The following conclusions can be drawn from our research for 2018-2020:

- mulberry leaf consumption can be saved by 15,3 $18,7 \%$ when silkworms are reared under cloth and film;

- as a result of the use of cloth and polyethylene film to retain high humidity, the number of feedings the larva with leaves at 1-5 instars decreased by 81,4-90,0, and the larva period was reduced to 2,7-4,0 days;

- most importantly, as a result of rearing silkworms under the fabric and film, a significant increase in the 


\section{EPRA International Journal of Research and Development (IJRD) \\ Volume: 6 | Issue: 1 | January 2021 - Peer Reviewed Journal}

growth and weight of larva was observed due to the constant maintenance of the hygrothermal regime;

- in the conditions of Uzbekistan in silkwormbreeding farms, it is recommended to rear silkworms under cloth and polyethylene film.

\section{ACKNOWLEDGEMENTS}

This research work of the author was completed in the range of practical project named "Creation of folding cocoon rack and silkworm lifter and the equipment's adapted in farms to make them" with number F-A-2018019 in the sponsorship of the Ministry of Innovative development of the Republic of Uzbekistan.

\section{REFERENCES}

1. Abdukodirov Sh. (2000). Excerpts from the history of our silkworm breeding. Tashkent, Fan, pp. 99-104.

2. Akhmedov N. (2014). Silkworm ecology and rearing agrotechnics (Manual). Tashkent

3. Akhmedov N., Daniyarov U. (2014). New technologies for developing sericulture. Tashkent, Davr.

4. Akhmedov N., Murodov S. (2004). Silkworm ecology and rearing agrotechnics. Study guide. Tashkent.

5. Bharat B., Satish V. (2014). Sericulture technologies developed by csrti mysore. Month \& Year of Publishing. - India, pp. 25-26.

6. Khomidy Kh., Papaskiry A.N. (2004). Individual variability of the phenotypic traits of the silkworm with changes in environmental factors. Scientific basis for solving urgent problems in the development of the silk industry. Tashkent, Fan. pp. 42-51.

7. Lavrentyev S.D. (1973). Study book for Silk Breeder. Moscow.

8. Mirzakhodjayev A, Mirzakhodjayev B.A, Soipov B. (2009). Research on the selection of types of cocoons. Scientific bases for solving urgent problems in the development of the silk industry. Tashkent, Fan. pp. 6266. 